\section{Medical Memorandum}

\section{A Simple Procedure for Early Detection of Hypofibrinogenaemia}

For the diagnosis of hypofibrinogenaemia or afibrinogenaemia the Kjeldahl or simpler " fibrindex " (Ortho) method is most frequently used. Weiner et al. (1953) suggested a " bedside " method, the so-called "clot-observation test." In cases suspected of afibrinogenaemia blood is withdrawn into a test-tube. If clotting has not occurred in 10 minutes, disturbance of the fibrinogen level can be assumed. One of us (G. L. B.) suggested the incorporation of this method in the admission routine, dispensing with the use of a test-tube. The following procedure has been used in our department for the past year:

In an cases of ante-partum haemorrhage the admitting house-surgeon takes off blood for cross-matching-a routine followed in most maternity units. He notes the time when taken and proceeds with the admission routine. Ten minutes later he observes the sample. If it has not clotted he considers the patient to be suffering from hypofibrinogenaemia. In cases where resuscitative action must be taken immediately-and it is in just such cases that a rapid diagnosis is needed-he can at once proceed and return to the sample later.

We believe hypofibrinogenaemia is not as rare as is usually suggested. Of the 2,176 cases admitted to the maternity unit of the North Middlesex Hospital during 1957, four had proved hypofibrinogenaemia or afibrinogenaemia (an incidence of 1 in 544), and two of these were diagnosed on admission by employing this simple test.

The first case was one of severe post-partum haemorrhage after a spontaneous unexplained stillbirth, where it was noted that the sample taken for cross-matching at the onset of the haemorrhage had not clotted. The patient later developed anuria, from which she subsequently recovered.

In the second case the afibrinogenaemia was associated with a ruptured uterus after external version under anaesthesia (Riedel, 1958). This patient died, and the diagnosis of both ruptured uterus and afibrinogenaemia was made in retrospect.

The third case was one of intrauterine death where the admitting house-surgeon noted poor clot formation, and a low fibrinogen level was subsequently confirmed biochemically. The level rectified itself spontaneously, in keeping with the findings of Hodgkinson et al. (1955) of fluctuating fibrinogen levels in those cases.

The fourth case is described in some detail, as it illustrates the efficacy of this method.

\section{Illustrative CASE .}

An emergency admission was arranged for the patient by her own doctor. He stated that she was a para-1 aged 25, booked for home confinement, who had had a severe antepartum haemorrhage at 38 weeks' maturity and who was in poor condition. She arrived at $7.30 \mathrm{a} . \mathrm{m}$. in the maternity receiving-room. She was pale and shocked, with a tense, tender uterus, and was losing moderately heavily per vaginam. Her blood pressure was $90 / 70 \mathrm{~mm}$. $\mathrm{Hg}$ and the pulse was feeble and rapid. No foetal heart could be heard. A catheter specimen showed the urine to be solid with albumin. Blood was taken immediately, an intravenous drip of "dextraven" begun, and morphine sulphate, $\frac{1}{4}$ gr. (16 mg.), given subcutaneously. At 7.45 a.m. one of us (J. A. R.) noted that the sample of blood had not clotted. (Subsequently absence of fibrinogen was confirmed.) The following measures were taken: (1) the dextraven was changed to group $\mathrm{O}, \mathrm{Rh}$ negative blood; (2) 6 pints $(3.4$ litres) of blood was ordered from the pathological labora- tory ; (3) a solution of fibrinogen was prepared; and (4) two bottles of triple-strength plasma were prepared.

At 8 a.m. infusion of triple-strength plasma was begun after the patient had had 1 pint $(570 \mathrm{ml}$.) of blood. Her pulse was still feeble and rapid. Vaginal bleeding continued, and it was noted that this blood showed no signs of clotting. As she reacted with a rigor to the plasma, given at speed. blood was given immediately afterwards.

At 9 a.m. the second bottle of triple-strength plasma was started. Her blood pressure remained low $(105 / 75 \mathrm{~mm} . \mathrm{Hg})$, but the pulse had improved in volume and was 90 . The blood then showed signs of clotting. A vaginal examination was carried out; the cervix was four fingerbreadths dilated. and the membranes, which were intact, were artificially ruptured. A second $400 \mathrm{ml}$. of plasma had been given by 9.15 a.m., and spontaneous delivery of a stillborn infant occurred at this time. Ergometrine maleate, $0.5 \mathrm{mg}$., was given intravenously with the birth of the anterior shoulder : the placenta, which followed immediately, was covered by a large, dark clot of $30 \mathrm{oz}$. $(850 \mathrm{ml}$.) (supporting the theory that afibrinogenaemia occurs after placental separation). Five units of " pitocin" were added to the next pint $(570 \mathrm{ml}$.) of blood, as there was a steady loss and the uterus tended to relax.

At 10 a.m. the fibrinogen was dissolved and ready for administration. By this time the patient had received 4 pints (2.2 litres) of blood and two bottles of triple-strength plasma. and $2.3 \mathrm{~g}$. of fibrinogen in $200 \mathrm{ml}$. of water was given slowly.

At 11 a.m. the blood clotted normally. The patient's condition was fair, her blood pressure being $100 / 60 \mathrm{~mm}$. $\mathrm{Hg}$, and there was a slight trickle of blood per vaginam. The pulse was 90 and of good volume. Two more pints $(1,140 \mathrm{ml}$.) of blood were given.

At 5 p.m. her condition was satisfactory; blood pressure $120 / 80 \mathrm{~mm}$. $\mathrm{Hg}$, pulse 86 . The total loss was estimated at $120 \mathrm{oz}$. (3.4 litres), which had been replaced by $120 \mathrm{oz}$. (3.4 litres) of blood, and two bottles of triple-strength plasma. That the loss was underestimated was proved two days later, when the haemoglobin (which had been $73 \%$ on admission) had fallen to $57 \%$.

The fibrinogen content of the blood was normal 26 hours after delivery, when the clotting-time was $4 \frac{1}{2}$ minutes.

\section{COMment}

In this case the diagnosis of hypofibrinogenaemia was made within 15 minutes of admission. Fibrinogen replacement had begun 15 minutes later. Within 90 minutes the patient had received $6 \mathrm{~g}$. of fibrinogen (in the form of concentrated plasma) and the blood showed signs of clotting. That, and the measures taken to prevent post-partum haemorrhage, made it possible for the patient to be discharged on the eleventh day, with a normal blood pressure, a trace of albumin in the urine, and a haemoglobin of $67 \%$.

The reasons why we think this method, which is only a slight improvement on the clot-observation test, is worth reporting are: because it is simple and does not need help from a laboratory, because it is applied routinely, and because the diagnosis can be made by an inexperienced housesurgeon soon after admission. Early diagnosis is of prime importance in the treatment of hypofibrinogenaemia.

We thank Mr. K. A. K. Hudson and Mr. A. W. Purdie to permission to report cases under their care.

\section{G. L. BOURNE, F.R.C.S., M.R.C.O.G. Senior Registrar.}

J. A. RIEDEL, F.R.C.S.Ed., D.Obst.R.C.O.G.. Registrar.
North Middlesex Hospital, London.

REFERENCES

Hodgkinson, C. P., Luzadre, J. H., Pifer, P. W., Swinehart, L. A.. and Remp, D. G." (1955). Obstet. and Gynec., 5, 465 . Riedel, J. A. (1958). J. Obstet. Gynaec. Brit. Emp., 65, 652. Weiner, A. E., Reid, D. B., and Roby, C. C. (1953). Amer. J. Obster.
Gynec., 66, 475. 